\title{
Effects of Intercropping with Bidens Species on Photosynthesis of Grape Seedlings under Cadmium Stress
}

\author{
Lisha Zhong ${ }^{1, a}$, Lijin Lin ${ }^{2, b}$, Dan Xia ${ }^{1, c}$ and Ming'an Liao ${ }^{1, d^{*}}$ \\ ${ }^{1}$ College of Horticulture, Sichuan Agricultural University, Chengdu, Sichuan, China \\ ${ }^{2}$ Institute of Pomology and Olericulture, Sichuan Agricultural University, Chengdu, Sichuan, China \\ a645627089@qq.com, 'llj800924@163.com, '1358068232@qq.com, Iman@sicau.edu.cn
}

${ }^{*}$ Corresponding author. Lisha Zhong and Lijin Lin contributed equally to this work.

Keywords: Intercropping; Grape; Photosynthesis; Bidens species; Cadmium

Abstract: A pot experiment was conducted to study the effects of intercropping with four Bidens species (Bidens bipinnata, Bidens pilosa, Bidens parviflora and Bidens biternata) on photosynthesis and soluble sugar content of grape seedlings under cadmium $(\mathrm{Cd})$ stress. The result showed that net photosynthetic rate $(\mathrm{Pn})$, stomatal conductance $(\mathrm{Gs}), \mathrm{CO}_{2}$ concentration of intercellular $(\mathrm{Ci})$ and transpiration rate (Tr) were decreased compared to monoculture. The soluble sugar content in roots and shoots significantly increased by intercropping compared to monoculture. Therefore, intercropping with four Bidens species inhibit the photosynthetic ability but improve the resistance to Cd stress of grapes.

\section{Introduction}

Cadmium (Cd), as a heavy metal element, can influence several physiological and biochemical processes such as water uptake, nutrient assimilation, photosynthesis, and respiration [1-2]. Some studies show that $\mathrm{Cd}$ stress result to photosynthesis inhibition for decreasing the contents of chlorophyll $\mathrm{a}$ and $\mathrm{b}$ [3]. Others indicate that $\mathrm{Cd}$ stress disturb the balance of phytohormone levels, and cause the decrease of photosynthetic capacity [4]. Grape as a major fruit in the world is also needed to be protected [5-6]. Some researches show appropriately intercropping can improve or reduce the photosynthetic performance of plants [7-8]. Intercropping different plants can reduce the biological stress and abiotic stress damage [9]. Bidens species are potential hyperaccumulators [10], and some studies show them can reduce the toxic effect of $\mathrm{Cd}$ on plants [11-12]. Therefore, in this study, we used four species of Bidens (B. bipinnata, B. pilosa, B. parviflora and B. biternata) to intercrop with grape seedlings under $C d$ stress by a pot experiment to study the effects on photosynthesis.

\section{Materials and Methods}

Materials. In April 2016, the seeds of four Bidens species B. bipinnata, B. pilosa, B. parviflora and $B$. biternata were collected from the surrounding farmland at Chengdu campus of Sichuan Agricultural University. Then, the seeds were put in the climate chamber to germination and further cultivation and transplanting. The species of the experimental cultivar of grape is Kyoho which cutting seedlings were purchased from Longquanyi area seedlings base of Chengdu in May 2016. The soil for the experiment was collected from the surrounding farmland at Chengdu campus of Sichuan Agricultural University in April 2016.

Experimental Design. The experiment was conducted in Chengdu Campus of Sichuan Agricultural University from April to July 2016. In April 2016, the soil was air-dried and passed through a 6.72-mm sieve. $3 \mathrm{~kg}$ air-dried soil was weighed into each plastic pot $(21 \mathrm{~cm} \mathrm{high,} 20 \mathrm{~cm}$ in diameter), soaking uniformly by $5 \mathrm{mg} / \mathrm{kg} \mathrm{Cd}$ (in the form of $\mathrm{CdCl}_{2} \cdot 2.5 \mathrm{H}_{2} \mathrm{O}$ ) solution for 4 weeks [13]. All pots were watered every day to keep the soil moisture about $80 \%$. In May 2016, three uniform-sized cutting seedlings (the shoots were about $15 \mathrm{~cm}$ ) of Kyoho grape were transplanted into pot for monoculture. Two uniform-sized seedlings (two true leaves expanded) of each four Bidens species and two grape seedlings were transplanted into each pot for intercropping. For each 
treatment with three replicates and the pots placed completely random. The distance between pots was $15 \mathrm{~cm}$, and the pot position exchanged pperiodically to weaken the impact of the marginal effects. The soil moisture content was maintained at $80 \%$ of field capacity until the plants were harvested.

After 60 days, the photosynthesis of each grape seedling was determined by using LI-6400 portable photosynthesis meter (LI-COR Inc., USA). The photosynthetic parameters of the photosynthesis meter were manual control $\mathrm{CO}_{2}$ concentration $400 \mu \mathrm{mol} \cdot \mathrm{mol}^{-1}$, temperature $30{ }^{\circ} \mathrm{C}$, light intensity $1000 \mu \mathrm{mol} \cdot \mathrm{m}^{-2} \cdot \mathrm{s}^{-1}$. The determination of photosynthetic parameters were net photosynthetic rate $(\mathrm{Pn})$, stomatal conductance $(\mathrm{Gs}), \mathrm{CO}_{2}$ concentration of intercellular $(\mathrm{Ci})$ and transpiration rate (Tr) [14]. Then, grape seedlings were dug up and divided into three parts of root, stem and leave, then washed with tap water firstly, followed by deionized water. After that, the tissues of all plants were dried at $80{ }^{\circ} \mathrm{C}$ until constant weight, weighed, ground to $<0.149 \mathrm{~mm}$ to determined the soluble sugar contents.

Statistical Analyses. Statistical analyses were conducted using statistical software of SPSS 17.0. Date were analyzed by one-way ANOVA with least significant difference at $5 \%$ confidence level.

\section{Results and Discussion}

Net Photosynthetic Rate (Pn). Intercropping with four Bidens species decreased the Pn of grape seedlings under $\mathrm{Cd}$ stress compared to monoculture (Fig. 1, $p<0.05$ ). The Pn of grape seedlings were ranked in the following order: monoculture > intercropping with $B$. pilosa $>$ intercropping with $B$. bipinnata $>$ intercropping with $B$. biternata $>$ intercropping with $B$. parviflora.

Stomatal Conductance (Gs). The Gs of grape seedlings intercropping with $B$. parviflora varied not obviously compared to monoculture under Cd stress (Fig. 2, $p<0.05$ ), but intercropping with the other three Bidens species decreased the Gs of grape seedlings. The Gs of grape seedlings by intercropping with B. bipinnata, B. pilosa, B. parviflora and B. biternata decreased by $25.80 \%$ ( $p<$ $0.05), 20.68 \%(p<0.05), 0.97 \%(p>0.05)$ and $48.18 \%(p<0.05)$ respectively compared to monoculture.

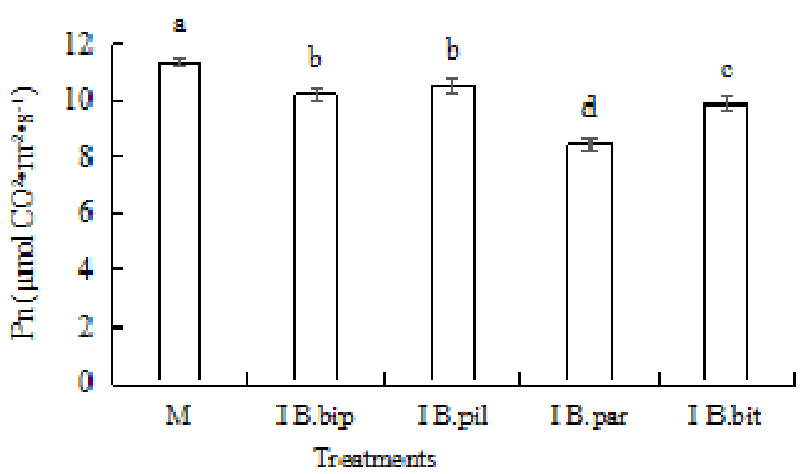

Fig. 1 Pn of grape seedlings. Different lowercase letters indicate significant differences based on one-way analysis of variance in SPSS 17.0 followed by the least significant difference test $(p<0.05) . \mathrm{M}=$ monoculture, IB.bip = intercropping with $B$. bipinnata, IB.pil = intercropping with $B$. pilosa, IB.par = intercropping with $B$. parviflora, IB.bit $=$ intercropping with $B$. biternata.

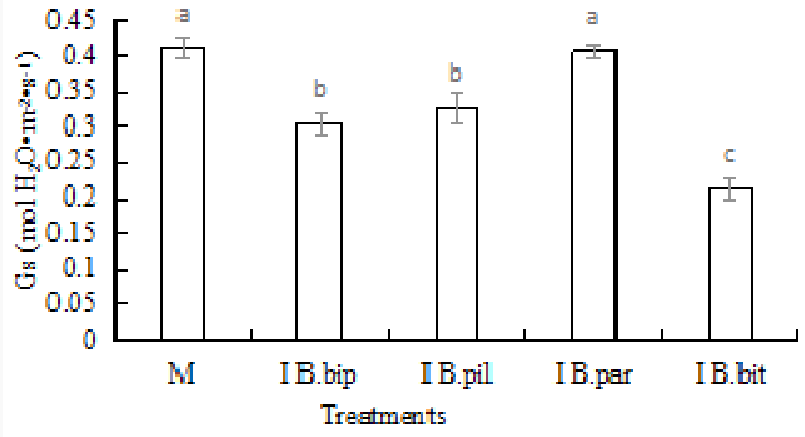

Fig. 2 Gs of grape seedlings. Different lowercase letters indicate significant differences based on one-way analysis of variance in SPSS 17.0 followed by the least significant difference test $(p<0.05) . \mathrm{M}=$ monoculture, IB.bip $=$ intercropping with $B$. bipinnata, IB.pil = intercropping with $B$. pilosa, IB.par = intercropping with $B$. parviflora, IB.bit = intercropping with $B$. biternata.

$\mathrm{CO}_{2}$ Concentration of Intercellular (Ci). Intercropping with four Bidens species decreased significantly the $\mathrm{Ci}$ of grape seedlings under $\mathrm{Cd}$ stress compared to monoculture (Fig. $3, p<0.05$ ). The $\mathrm{Ci}$ of grape seedlings were ranked in the following order: monocultur > intercropping with $B$. 
bipinnata $>$ intercropping with $B$. parviflora $>$ intercropping with $B$. pilosa $>$ intercropping with $B$. biternata.

Transpiration Rate (Tr). Compared with the monoculture, the $\mathrm{Tr}$ of grape seedlings decreased significantly by intercropping under $\mathrm{Cd}$ stress (Fig. $4, p<0.05$ ). The $\operatorname{Tr}$ of grape seedlings were ranked as: monoculture > intercropping with $B$. bipinnata $>$ intercropping with $B$. pilosa > intercropping with $B$. parviflora > intercropping with $B$. biternata. The $\mathrm{Tr}$ of grape seedlings by intercropping with B. bipinnata, B. pilosa, B. parviflora, and B. biternata, decreased by $9.92 \%$, $19.39 \%, 32.16 \%$ and $35.93 \%$ respectively compared to monoculture.

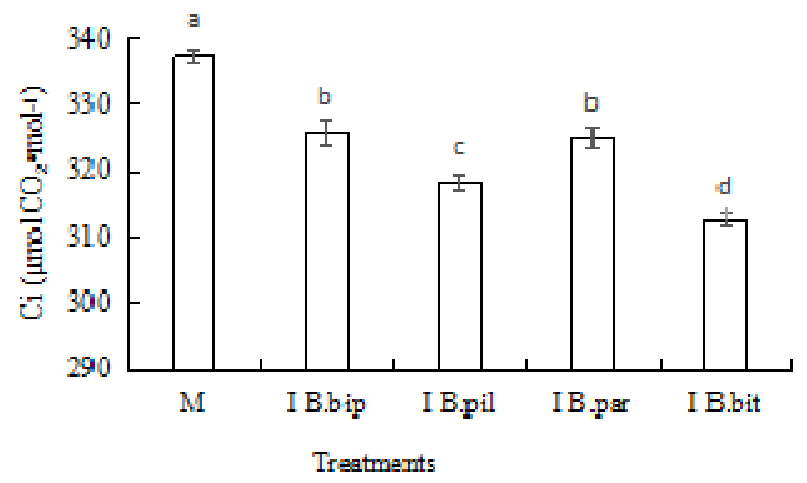

Fig. $3 \mathrm{Ci}$ of grape seedlings. Different lowercase letters indicate significant differences based on one-way analysis of variance in SPSS 17.0 followed by the least significant difference test $(p<0.05) . \quad \mathrm{M}=$ monoculture, IB.bip $=$ intercropping with $B$. bipinnata, IB.pil = intercropping with B. pilosa, IB.par = intercropping with $B$. parviflora, IB.bit = intercropping with $B$. biternata.

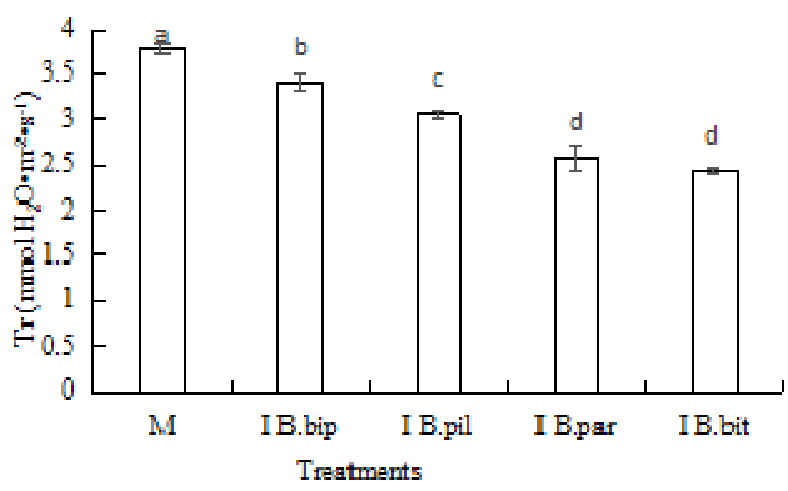

Fig. 4 Tr of grape seedlings. Different lowercase letters indicate significant differences based on one-way analysis of variance in SPSS 17.0 followed by the least significant difference test $(p<0.05) . \quad \mathrm{M}=$ monoculture, IB.bip = intercropping with $B$. bipinnata, IB.pil = intercropping with B. pilosa, IB.par = intercropping with $B$. parviflora, IB.bit = intercropping with $B$. biternata.

Soluble Sugar Content of Grape Seedlings. Intercropping significantly increased the soluble sugar content in roots and shoots of grape seedlings under $\mathrm{Cd}$ stress compared to monoculture (Table $1, P<0.05$ ). The soluble sugar content in roots of grape seedlings was ranked as: intercropping with $B$. pilosa $>$ intercropping with $B$. biternata $>$ intercropping with $B$. parviflora $>$ intercropping with $B$. bipinnata > monoculture. Intercropping with B. bipinnata, $B$. pilosa, $B$. parviflora and $B$. biternata increased the soluble sugar content in stems of grape seedlings by $11.38 \%, 22.57 \%, 24.89 \%$, and $19.17 \%$ compared to monoculture, respectively. For the leaves of grape seedlings, the order was intercropping with $B$. parviflora $>$ intercropping with $B$. biternata $>$ intercropping with $B$. bipinnata $>$ intercropping with $B$. pilos $a>$ monoculture. For the soluble sugar content in shoots of grape seedlings, intercropping with B. bipinnata, B. pilosa, B. parviflora and $B$. biternata increased respectively by $12.71 \%, 9.90 \%, 19.68 \%$ and $18.77 \%$ compared to monoculture.

\section{Conclusions}

In this study, intercropping with four Bidens species B. bipinnata, B. pilosa, B. parviflora and B. biternata decreased the $\mathrm{Pn}, \mathrm{Gs}, \mathrm{Ci}$ and $\mathrm{Tr}$ of grape seedlings generally under $\mathrm{Cd}$ stress. Intercropping with four Bidens species increased the soluble sugar content in roots and shoots of grape seedlings under $\mathrm{Cd}$ stress. In conclusion, intercropping with four Bidens species inhibit the photosynthetic ability but improve the resistance to $\mathrm{Cd}$ stress of grape.

\section{Acknowledgements}

This work was financially supported by the Application Infrastructure Project of Science and Technology Department of Sichuan Province (2016JY0258). 
Table 1 Soluble sugar content in grape seedlings

\begin{tabular}{|l|c|c|c|c|}
\hline \multicolumn{1}{|c|}{ Treatments } & $\begin{array}{c}\text { Roots } \\
(\mathrm{mg} / \mathrm{g})\end{array}$ & $\begin{array}{c}\text { Stems } \\
(\mathrm{mg} / \mathrm{g})\end{array}$ & $\begin{array}{c}\text { Leaves } \\
(\mathrm{mg} / \mathrm{g})\end{array}$ & $\begin{array}{c}\text { Shoots } \\
(\mathrm{mg} / \mathrm{g})\end{array}$ \\
\hline \multicolumn{1}{|c|}{ Monoculture } & $0.518 \pm 0.081 \mathrm{c}$ & $0.445 \pm 0.076 \mathrm{e}$ & $0.751 \pm 0.234 \mathrm{~d}$ & $0.654 \pm 0.130 \mathrm{c}$ \\
\hline Intercropping with B. bipinnata & $0.575 \pm 0.135 \mathrm{~b}$ & $0.503 \pm 0.089 \mathrm{~d}$ & $0.867 \pm 0.259 \mathrm{~b}$ & $0.749 \pm 0.205 \mathrm{~b}$ \\
\hline Intercropping with B. pilosa & $0.651 \pm 0.058 \mathrm{a}$ & $0.575 \pm 0.123 \mathrm{~b}$ & $0.797 \pm 0.186 \mathrm{c}$ & $0.726 \pm 0.162 \mathrm{~b}$ \\
\hline Intercropping with B. parviflora & $0.637 \pm 0.128 \mathrm{a}$ & $0.593 \pm 0.073 \mathrm{a}$ & $0.907 \pm 0.183 \mathrm{a}$ & $0.814 \pm 0.152 \mathrm{a}$ \\
\hline Intercropping with B. biternata & $0.639 \pm 0.082 \mathrm{a}$ & $0.551 \pm 0.066 \mathrm{c}$ & $0.899 \pm 0.137 \mathrm{ab}$ & $0.805 \pm 0.130 \mathrm{a}$ \\
\hline
\end{tabular}

Values are mean \pm SE. Different lowercase letters indicate significant differences based on one-way analysis of variance in SPSS 17.0 followed by the least significant difference test $(p<0.05)$.

\section{References}

[1] P.K. Singh and R.K. Tewari: Journal of Environmental Biology Vol. 24 (2003), p. 107.

[2] M.K. Daud, Q.L. He, L. Mei, B. Ali and S.J. Zhu: Chemosphere Vol. 120 (2015), p. 309.

[3] J.Y. Sun and Z.G. Sen: Chinese Journal of Applied Ecology Vol. 18 (2007), p. 2605.

[4] K. Wu, Z.H. Wu, F.J. Tai, Y. Han, B.E. Xie and Z.L. Yuan: Acta Ecologica Sinica Vol. 31 (2011), p. 4517.

[5] J.T. Li, J.W. Qiu, X.W. Wang, Y. Zhong, C.Y. Lan and W.S. Shu: Environmental Pollution Vol. 143 (2006), p. 159.

[6] M.N. Chen, M.F. Guan, C.L. Hu and M.C. Li: Southern Agricultural Machinery Vol. 1 (2016), p. 20.

[7] L.A. Thrupp: International Affairs Vol. 76 (2000), p. 283.

[8] G.X. Su, W.L. Din, J.B. Liu, M. Li, Z. Wang and B.C. Xu: Journal of Plant Resources and Environment Vol. 26 (2017), p. 10.

[9] X.B. Peng, Y.Y. Zhang, J. Cai, Z.M. Jiang and S.X. Zhang: Agroforest Syst Vol. 76 (2009), p. 569.

[10]X.J. Ren, D.H. Zhu, H.Q. Wu and D.F. Wu: Resource Development \& Market Vol. 30 (2014), p. 961.

[11] K.W. Huang, M.A. Liao and L.J. Lin: Journal of Ecology and Rural Environment Vol. 31 (2015), p. 753.

[12] J.Chen, M.A. Liao, L.J. Lin, J. Liu, F.Y. Tang, L. Luo, L.Y. Mei and Y. Liu: Acta Agriculturae Boreali-Sinica Vol. 28 (2013), p. 153.

[13] Y.T. Cao, X.H. Peng, Q. Lei and L.J. Lin: Shaanxi Journal of Agricultural Sciences Vol. 61 (2015), p. 61.

[14]Z.H. Zhang, Z.Y. Cheng, G.Q. Zhang and R. Zhang: Journal of Irrigation and Drainage Vol. 33 (2014), p. 130. 